\title{
Influência da adubação química e orgânica no crescimento inicial e acúmulo de nutrientes em variedade de milho crioulo
}

\section{Influence of chemical and organic fertilization on the growth and nutrient accumulation in variety of maize landrace}

\author{
Katiana de Sousa Vale ${ }^{1}$, Ednaldo Barbosa Pereira Junior $*^{2}$, Oscar Mariano Hafle $3^{2}$, Joice Xavier de Sousa ${ }^{1}$, Maria José \\ Estevão P. Barbosal , Januária Caldeira Sousa ${ }^{1}$, Hermano Oliveira Rolim ${ }^{4}$
}

Resumo: Este trabalho teve como objetivo avaliar fontes de adubação orgânica em substituição mineral no desenvolvimento e absorção de nutriente no milho crioulo. O experimento foi realizado no Instituto Federal de Educação, Ciência e Tecnologia da Paraíba, no Município de Sousa-PB, situando a $233 \mathrm{~m}$ de altitude, com latitude de $6^{\circ} 45^{\prime}$ sul e longitude de $38^{\circ} 13^{\prime}$ oeste. O delineamento experimental utilizado foi o de blocos ao acaso (DBC) com 3 repetições e 5 tratamentos, totalizando 15 parcelas com $272 \mathrm{~m}^{2}$ cada. Os tratamentos foram compostos por: T = testemunha (sem adubo), A.Q = Adubação química (30 Kg de N por ha), E.B = esterco bovino $\left(4,2 \mathrm{t} \mathrm{ha}^{-1}\right)$, E.O = esterco ovino $\left(2,2 \mathrm{t} \mathrm{ha}^{-1}\right)$ e E.A = Esterco de aviário $\left(2,0 \mathrm{t}\right.$ ha $\left.{ }^{-1}\right)$. Foram analisados altura de planta, diâmetro do colmo, matéria verde da parte aérea, matéria seca da parte aérea e teores de $\mathrm{N}$, $\mathrm{P}$ e $\mathrm{K}$ na biomassa do milho. Os tratamentos testados influenciaram em todas as variáveis analisadas. As fontes orgânicas são promissoras na substituição total á adubação química, com destaque para o esterco de aviário. A extração de $\mathrm{N}$ pela planta seguiu a seguinte ordem: esterco ovino, adubação química, esterco bovino e adubação química, de acordo com as datas coletadas. A extração de P pela planta seguiu a seguinte ordem: esterco aviário, esterco ovino, esterco bovino e esterco bovino, de acordo com as datas coletadas. A extração de K pela planta seguiu a seguinte ordem: esterco ovino, esterco bovino, adubação química e esterco de aviário, de acordo com as datas coletadas.

Palavras - chaves: Absorção, adubação orgânica, milho crioulo

\begin{abstract}
This work aimed to evaluate sources of organic fertilizer in mineral replacement in the development and nutrient absorption in maize landraces. The experiment was conducted at the Federal Institute of Education, Science and Technology of Paraiba, in the municipality of Sousa -PB, standing at 233 meters above sea level, with latitude 645 ' south and longitude 38 13 ' west. The experimental design was randomized blocks (DBC) with 3 replications and 5 treatments, totaling 15 plots with $272 \mathrm{~m}^{2}$ each. The treatments were: $\mathrm{T}=$ control (without fertilizer), AQ = Chemical fertilization $(30 \mathrm{~kg} \mathrm{~N}$ per ha), EB = manure $\left(4.2 \mathrm{t} \mathrm{ha}^{-1}\right), \mathrm{EO}=$ sheep manure $\left(2.2 \mathrm{t} \mathrm{ha}^{-1}\right)$ and $\mathrm{E} . \mathrm{a}=$ poultry manure $\left(2.0 \mathrm{t} \mathrm{ha}^{-1}\right)$. Plant height were analyzed, stem diameter, green mass of shoot, dry weight of shoots and concentrations of N, P and K in the biomass of corn. The treatments influenced in all variables. The organic sources are promising in total replacement will chemical fertilizer, especially the poultry manure. The extraction of $\mathrm{N}$ by the plant followed the order: sheep manure, chemical fertilizer, cattle manure and chemical fertilizer, according to the collected dates. The extraction of the plant $\mathrm{P}$ followed the order: avian manure, sheep manure, cattle manure and cattle manure, according to the collected dates. The extraction of $\mathrm{K}$ by the plant followed the order: sheep manure, cattle manure, chemical fertilizer and poultry manure, according to the collected dates.
\end{abstract}

Key words: Absorption, organic fertilizer, corn creole.

\footnotetext{
*Autor para correspondência

Recebido para publicação em 20/12/2014; aprovado em 14/03/2015

${ }^{1}$ Tecnólogo em Agroecologia, Instituto Federal da Paraíba - IFPB Campus Sousa. Rua presidente Tancredo Neves s/n Sousa-PB. E - mail: katianasv.eco@gmail.com

${ }^{2}$ Geógrafo. D. Sc. Professor do Instituto Federal da Paraíba - IFPB Campus Sousa. Rua presidente Tancredo Neves s/n Sousa-PB. E - mail: ebpjr2@hotmail.com

${ }^{3}$ Agrônomo, D.Sc., Professor do Instituto Federal da Paraíba - IFPB Campus Sousa. Rua Presidente Tancredo Neves s/n. E-mail: omhafle@ yahoo.com.br.

${ }^{4}$ Agronômo, M.Sc. Instituto Federal a Paraíba - IFPB Campus. Rua Presidente Tancredo Neves s/n Sousa-PB, E-mail: rolimano@ hotmail.com
} 


\section{INTRODUÇÃO}

O milho (Zea mays L.) é utilizado na alimentação e sua importância econômica é caracterizada pelas diversas formas de sua utilização, que vai desde a alimentação animal até a indústria de alta tecnologia. Em função de seu potencial produtivo, composição química e valor nutritivo, o milho constitui-se em um dos mais importantes cereais cultivados e consumidos no mundo (PORTO., 2010).

A cadeia produtiva do milho é uma das mais importantes do agronegócio brasileiro, o qual, considerando apenas a produção primária, responde por $37 \%$ da produção nacional de grãos. A demanda crescente, tanto interna como externa, reforça o grande potencial do setor. Junto com a soja, o milho é insumo básico para a avicultura e a suinocultura, dois mercados extremamente competitivos internacionalmente e geradores de receita para o Brasil (CALDARELLI; BACCHI, 2012).

A importância do milho não está apenas na produção de uma cultura anual, mas em todo o relacionamento que essa cultura tem na produção agropecuária brasileira, tanto no que diz respeito a fatores econômicos quanto a fatores sociais Pela sua versatilidade de uso, pelos desdobramentos de produção animal e pelo aspecto social, o milho é um dos mais importantes produtos do setor agrícola no Brasil (CRUZ et al., 2006).

Cerca de $94 \%$ dos produtores de milho no Brasil se caracterizam como agricultores familiares, com baixa utilização de insumos e cultivo em condições desfavoráveis para o bom desenvolvimento e altas produtividades da cultura (DUARTE., 2002). Segundo Meneguetti et al. (2002), uma alternativa para pequenos agricultores é a utilização de variedades locais que possibilitam a produção de sementes próprias.

O milho é uma cultura altamente exigente em nutrientes e geralmente responde a doses altas de adubos. A adubação, quando tomada isoladamente, é a técnica que traz maior retorno em produtividade e rentabilidade. $\mathrm{O}$ manejo nutricional é um dos pilares fundamentais para aperfeiçoar o resultado dos sistemas de produção de milho no mundo (MELGAR; TORRES DUGGAN, 2004).

Segundo Pires e Junqueira (2001), quimicamente, a adubação orgânica é importante fonte de nutrientes, especialmente N, P, $\mathrm{S}$ e micronutrientes, sendo a única forma de armazenamento de $\mathrm{N}$ que não volatiliza e, ainda, responsável por $80 \%$ do fósforo total encontrado no solo.

$\mathrm{Na}$ época da revolução verde, o desafio era obter maior produtividade na agricultura convencional. Atualmente é desenvolver uma agricultura que cause um menor impacto ambiental ao ambiente e aos recursos naturais. Os adubos químicos também chamados de pacotes tecnológicos eram adquiridos para adubar o solo e ter uma maior produção das culturas. Diante deste fato, torna-se necessário buscar alternativas através de fontes orgânicas em substituição aos adubos sintéticos como proposta de condicionamento do solo ao ponto de produzir na estimativa esperada, voltando a ser

Tabela 1. Atributos químicos do solo da área experimental.

$\begin{array}{lllll}\mathrm{pH} & \mathrm{P} & \mathrm{K} & \mathrm{Na} & \mathrm{Ca}\end{array}$

$\mathrm{H}_{2} \mathrm{O} \quad \mathrm{mg} \mathrm{dm}^{-3}$

7,2 23

$23 \quad 0,39$

0,07

2,3

$\mathrm{cmol}_{\mathrm{c}} \mathrm{dm}^{-3}$

um cereal de boa qualidade, viável, econômico ambientalmente correto para a agricultura familiar.

$\mathrm{O}$ uso contínuo dos adubos sintéticos de forma descontrolada vem causando sérios problemas de degradação do solo, por provocar uma rápida redução do teor da matéria orgânica, salinização, erosão, e empobrecimento de nutrientes da solução do solo ao longo dos anos (SILVA et al., 2007).

$\mathrm{O}$ estudo da marcha de absorção de nutrientes e do acúmulo de matéria seca, em função dos estádios fenológicos da cultura do milho, é de fundamental importância para subsidiar estratégias de definição das quantidades e das épocas de realização de adubações e das quantidades mínimas que devem ser restituídas ao solo para fins de manutenção da fertilidade (VON PINHO et al., 2009).

A marcha de absorção de nutrientes na cultura do milho pode ser afetada pelo clima, pelas cultivares e pelos sistemas de cultivo. De modo geral, pode-se dizer que os nutrientes são absorvidos durante todo o ciclo, sendo as diferenças verificadas nas velocidades de absorção destes em função do ciclo e na sua translocação das folhas e dos colmos para os órgãos reprodutivos (ANDRADE et al., 1975). A absorção de nutrientes logo no início do ciclo da cultura do milho é mínima, pois as reservas contidas nas sementes são suficientes para as necessidades iniciais da planta (STIPP; YAMADA, 1988).

O objetivo deste trabalho foi avaliar fontes de adubação orgânica em substituição mineral no desenvolvimento e absorção de nutriente no Milho crioulo.

\section{MATERIAL E MÉTODOS}

O trabalho foi realizado em uma área experimental no Instituto Federal de Educação, Ciência e Tecnologia da Paraíba, Campus Sousa-PB, de Abril à Junho de 2014. A localidade situa-se a $233 \mathrm{~m}$ de altitude, com latitude sul de $6^{\circ}$ $45^{\prime}$ e longitude oeste de $38^{\circ} 13^{\prime}$. O clima é semiárido quente do tipo BSH da classificação de Koppen, ou seja, a evaporação é maior do que a precipitação. A pluviosidade média anual é de $654 \mathrm{~mm}$ ano, com chuvas concentradas no período de janeiro a junho. A temperatura média é de $28^{\circ} \mathrm{C}$, enquanto que a umidade relativa do ar é de $64 \%$. Em um solo do tipo Planossolo, com relevo plano, e textura superficial franco-arenosa (EMBRAPA., 2006)

O delineamento experimental utilizado foi o de blocos ao acaso (DBC) com 3 repetições e 5 tratamentos, totalizando 15 parcelas com $272 \mathrm{~m}^{2}$ cada. Os tratamentos foram compostos por: $\mathrm{T}=$ testemunha (sem adubo), A.Q = Adubação química (30 Kg de $\mathrm{N}$ por ha), E.B = esterco bovino $\left(4,2 \mathrm{t} \mathrm{ha}^{-1}\right), \mathrm{E} \cdot \mathrm{O}=$ esterco ovino $\left(2,2 \mathrm{t} \mathrm{ha}^{-1}\right)$ e E. A = esterco aviário $\left(2,0 \mathrm{t} \mathrm{ha}^{-1}\right)$. Para realização das adubações nos diferentes tratamentos foi coletado amostra de solo da área experimental para analisar os atributos químicos (tabela 1) e dos percentuais de $\mathrm{N}$ nas fontes orgânicas e mineral (tabela 2). Com base nestes parâmetros foi determinada a quantidade por fontes em g/cova a ser aplicado em cada tratamento de acordo com a exigência nutricional de $\mathrm{N}$ para a cultura do milho, segundo a recomendação da Comissão Estadual de Fertilidade do Solo de Pernambuco (2008).

P, K: Extrator Mehlich 1M; Al, Ca, Mg: Extrator KCL 1M; H + Al: Extrator Acetato de Cálcio 0,5 M, pH 7,0:em $\mathrm{H}_{2} \mathrm{O}$; Matéria orgânica: Digestão

Úmida Walkley-Black. 
Tabela 2: Valores percentuais de N, P e K das fontes orgânicas e minerais utilizadas no cultivo do milho crioulo, IFPB Campus Sousa, 2014.

\begin{tabular}{|c|c|c|c|}
\hline Fontes & $\mathbf{N}$ & $\mathrm{P}$ & K \\
\hline Esterco bovino & 0.7 & 005 & 08 \\
\hline Esterco ovino & 1,35 & 0,03 & 0,7 \\
\hline Esterco aviário & 1,44 & 0,03 & 1,5 \\
\hline Uréia & 45 & --- & ---- \\
\hline
\end{tabular}

Em março de 2014 foi realizado o preparo do solo com duas gradagens cruzadas para incorporar o resíduo das plantas existentes na área, depois a demarcação das parcelas. Cada parcela experimental foi composta por quatro linhas de cinco metros com espaçamento de $80 \mathrm{~cm}$ entre linhas e $40 \mathrm{~cm}$ entre plantas. As covas foram feitas com $20 \mathrm{~cm}$ de profundidade sendo adicionados os tratamentos na profundidade de $15 \mathrm{~cm}$ depois coberto com solo. No dia primeiro de maio foi realizado a semeadura colocando 3 sementes por cova. Sendo utilizado sementes crioula de milho (cv. Porto Rico de porte alto e ciclo tardio) oriundas do banco de sementes do Assentamento Santo Antônio, Cajazeiras - PB.

As adubações (tratamentos) foram parceladas nas seguintes formas $40 \%$ da fonte na fundação (antes do plantio) os $60 \%$ restantes em duas vezes. Após 10 dias da emergência foi realizado o desbaste deixando apenas uma planta por cova, no dia posterior realizou-se a primeira adubação (30\%) a segunda (30\% restante) foi realizada com 15 dias após a primeira. Para aplicação da adubação restante foram realizadas um sulco a $10 \mathrm{~cm}$ da planta com aproximadamente $5 \mathrm{~cm}$ de profundidade em cada linha da parcela experimental.

Para o controle de plantas espontâneas foram efetuadas capinas manual com auxílio de enxada sempre que necessário. Para prevenção e controle de lagarta da espiga (Helicoverpa zea) e pulgão-do-milho (Rhopalosi phummaidis) foi utilizado defensivo alternativo a base de cebolinha verde e fumo de corda, aplicados duas vezes por semana de forma alternada dentro dos princípios agroecológicos. Foram realizadas irrigações diárias com sistema de irrigação por microaspersão, procurando fornecer uma quantidade de água suficiente para o bom desenvolvimento da cultura.

Para coleta de dados foi considerado apenas as fileiras centrais como área útil, coletando duas plantas de cada parcela de forma aleatória, onde foram feitas as seguintes avaliações: altura da planta $(\mathrm{cm})$ : obtido com o auxílio de uma trena medindo-se do nível do solo até a parte apical de cada planta, diâmetro do colmo $(\mathrm{mm})$ : medição foi realizada utilizando paquímetro digital, matéria verde da parte aérea (g/planta): foi pesada em balança digital para obtenção do peso, matéria seca da parte aérea (g/planta): o material vegetal foi acondicionado no saco de papel, colocado na estufa de circulação de ar a $650 \mathrm{C}$ por 72 horas, determinação de N, P e K na biomassa do milho: Para a determinação de N, $\mathrm{P}$ e $\mathrm{K}$ foi triturado o material vegetal seco no moinho de facas willey. O nitrogênio foi realizado conforme a metodologia de TEDESCO et al. (1995), para fósforo e potássio foi realizada conforme a metodologia de MALAVOLTA et al. (1989). Todas as análises foram realizada no laboratório de análise de solo, água e planta (LASAP) pertencente ao IFPB Campus Sousa.

Os dados foram submetidos análise de variância e quando significativo utilizado o teste Tukey ao nível $(\mathrm{P}<0,01)$ e $(\mathrm{P}<0,05)$ para comparação as médias, através de aplicativo ASSISTAT 7.5 (SILVA \& AZEVEDO., 2002).

\section{RESULTADOS E DISCUSSÃO}

Analisando altura de planta do milho na tabela 3, observase que não houve significância entre os tratamentos onde se manteve uniforme aos 12, 22 e 32 (DAE). Provavelmente, Isto se deve ao fato de que as plantas, em sua fase inicial, utilizam as reservas provenientes do cotilédone e dessa forma, o processo de fotossíntese apresenta pouca contribuição no crescimento da planta (TAIZ; ZEIGER., 2004).

Ocorreram diferenças significativos $(\mathrm{P}<0,05)$ apenas aos 42 (DAE) (tabela 3), os maiores resultados da altura de planta foram 1,66 m (esterco de aviário) e 1,48 m (adubação química). A cama de aviário consegue promover o desenvolvimento do milho ao ponto de aferir resultado maior do que adubação química, devido provavelmente, por manter o solo superficialmente mais úmido, facilitar a infiltração de água, manter os nutrientes mais disponíveis, conservar a estrutura do solo, além de fornecer nutrientes, principalmente N (SOUZA., 1998).

Avaliando fontes orgânicas e adubação mineral Guareschi et al. (2013) concluiu que o aumento das doses de esterco bovino até $40 \mathrm{Mg}$ ha-1 propiciou altura de planta com 67,9 $\mathrm{cm}$, já com doses crescentes de cama de frango aferiu $61,3 \mathrm{~cm}$ com aplicação de $25,76 \mathrm{Mg}$ ha-1, aos 60 dias após emergência na cultura do milho.

Tabela 3- Altura de planta em cada coleta para os diferentes tratamentos, na cultura do milho crioulo. IFPB, Sousa, 2014.

\begin{tabular}{|c|c|c|c|c|}
\hline \multirow{3}{*}{ Tratamentos } & \multicolumn{4}{|c|}{ ALTURA DE PLANTAS (m) } \\
\hline & \multicolumn{4}{|c|}{ Dias após emergência (DAE) } \\
\hline & 12 & 22 & 32 & 42 \\
\hline $\mathrm{T}$ & $0,26 \mathrm{a}$ & $0,48 \mathrm{a}$ & $1,02 \mathrm{a}$ & $1,42 \mathrm{ab}$ \\
\hline A.Q & $0,23 \mathrm{a}$ & $0,46 \mathrm{a}$ & $1,06 \mathrm{a}$ & $1,48 \mathrm{ab}$ \\
\hline E. B & $0,26 \mathrm{a}$ & $0,49 \mathrm{a}$ & $0,97 \mathrm{a}$ & $1,26 \mathrm{~b}$ \\
\hline E. $\mathrm{O}$ & $0,30 \mathrm{a}$ & $0,48 \mathrm{a}$ & $0,95 \mathrm{a}$ & $1,35 \mathrm{ab}$ \\
\hline E. A & $0,32 \mathrm{a}$ & $0,55 \mathrm{a}$ & $1,05 \mathrm{a}$ & $1,66 \mathrm{a}$ \\
\hline
\end{tabular}

$\begin{array}{lccc}\mathbf{C V}(\%) & 16,1 & 11,9 & 9,2 \\ \mathbf{T}=\text { Testemunha (sem adubação), A.Q = Adubação química, E.B = Esterco bovino, E.O = Esterco ovino, E.A = Esterco de aviário. Médias seguidas de } \\ \text { mesma letra na coluna, não diferem entre si pelo teste de Tukey a 5\% de probabilidade. }\end{array}$


Analisando o diâmetro do colmo na tabela 4, observa-se que houve diferença significativa entre os tratamentos testados aos 12 dias após a semeadura (DAE). Destacando-se o adubo químico (A.Q) dos demais com 13,57 mm. Tal fato pode ser justificado pela melhor eficiência e pronta disponibilidade do $\mathrm{N}$ oriundo da fonte de uréia utilizada, consequientemente, ocorreram aumento na quantidade de nutrientes disponíveis (DAGA et al., 2009). As demais coletas aos 22, 32 e 42 DAE não foram influenciados pelos diferentes tratamentos. O diâmetro do colmo é uma característica de grande importância, pois plantas com maior diâmetro basal são menos sujeitas ao tombamento e quebramento e facilitam a colheita do milho verde (PEREIRA et al., 2012).
Cruz et al. (2008) afirma que normalmente, o diâmetro do colmo apresenta correlação com a produtividade por se tratar de um órgão de reserva da planta, e seu comportamento influencia diretamente no desempenho dos grãos. Pereira Júnior et al. (2012) comparando diferentes fontes e doses de adubos orgânicos no cultivo do milho crioulo não encontrou diferenças entre as médias. Para o diâmetro do colmo. Mesmo assim, entre as fontes testadas os tratamentos com esterco de ovino e cama de aviário apresentaram as melhores respostas comparadas com os demais. Pode-se observar que estas fontes orgânicas se tornam promissoras para substituir a adubação química.

Tabela 4- Diâmetro do colmo em cada coleta para os diferentes tratamentos, na cultura do milho crioulo. IFPB, Sousa, 2014.

\begin{tabular}{|c|c|c|c|c|}
\hline \multirow{3}{*}{ Tratamentos } & \multicolumn{4}{|c|}{ DIÂMETRO DO COLMO (mm) } \\
\hline & \multicolumn{4}{|c|}{ Dias após emergência (DAE) } \\
\hline & 12 & 22 & 32 & 42 \\
\hline $\mathrm{T}$ & $7,59 \mathrm{~b}$ & $12,20 \mathrm{a}$ & $20,92 \mathrm{a}$ & $19,87 \mathrm{a}$ \\
\hline A.Q & $13,57 \mathrm{a}$ & $14,19 \mathrm{a}$ & $22,16 \mathrm{a}$ & $22,41 \mathrm{a}$ \\
\hline E. B & $9,18 \mathrm{~b}$ & $14,93 \mathrm{a}$ & $21,44 \mathrm{a}$ & $19,21 \mathrm{a}$ \\
\hline E. O & $7,86 \mathrm{~b}$ & $13,26 \mathrm{a}$ & $21,64 \mathrm{a}$ & $20,19 \mathrm{a}$ \\
\hline E. A & $8,00 \mathrm{~b}$ & $15,49 \mathrm{a}$ & $18,94 \mathrm{a}$ & $23,37 \mathrm{a}$ \\
\hline CV (\%) & 13,8 & 12,4 & 9,9 & 8,7 \\
\hline
\end{tabular}

T = Testemunha (sem adubação), A.Q = Adubação química, E.B = Esterco bovino, E.O = Esterco ovino, E.A = Esterco de aviário. Médias seguidas de mesma letra na coluna, não diferem entre si pelo teste de Tukey a $1 \%$ de probabilidade.

Ocorreu diferença significativa no peso da matéria verde da parte aérea aos 22 e 42 dias após a emergência a $(\mathrm{P}<0,01)$ destacando-se aos 22 dias a adubação química (A.Q) seguida do esterco bovino (E.B). Analisando aos 42 dias destaca-se a cama de aviário seguido do esterco bovino (tabela 5).

Ainda na tabela 5, percebe-se que aos 22 dias o resultado encontrado pela a adubação química (A.Q) foi superior aos demais tratamentos porém, os tratamentos com esterco bovino (E.B), esterco ovino(E.O) e esterco de aviário (E.A) foram superiores a testemunha(T). Aos 42 dias o adubo com cama de aviário foi superior a todos os tratamentos testados. A mesma conseguiu promover o desenvolvimento da do milho crioulo, devido provavelmente, por manter o solo superficialmente mais úmido, facilitar a infiltração de água, manter os nutrientes mais disponíveis, conservar a estrutura do solo, além de fornecer nutrientes, principalmente $\mathrm{N}$ (SOUZA., 1998).

Tabela 5- Matéria verde da parte aérea (MVPA) em cada coleta para os diferentes tratamentos, na cultura do milho crioulo. IFPB, Sousa - PB, 2014.

\begin{tabular}{|c|c|c|c|c|}
\hline \multirow{3}{*}{ Tratamentos } & \multicolumn{4}{|c|}{ MATÉRIA VERDE DA PARTE AÉREA (g/planta) } \\
\hline & \multicolumn{4}{|c|}{ Dias após emergência (DAE) } \\
\hline & 12 & 22 & 32 & 42 \\
\hline $\mathrm{T}$ & $54,79 \mathrm{a}$ & $108,40 b$ & $560,37 \mathrm{a}$ & $797,04 \mathrm{~b}$ \\
\hline A.Q & $44,49 \mathrm{a}$ & $268,00 \mathrm{a}$ & $708,04 \mathrm{a}$ & $887,02 \mathrm{ab}$ \\
\hline E. B & $49,85 \mathrm{a}$ & 234,81 a & $605,70 \mathrm{a}$ & $781,35 \mathrm{~b}$ \\
\hline E. O & $59,02 \mathrm{a}$ & $169,85 \mathrm{ab}$ & $641,37 \mathrm{a}$ & $794,69 \mathrm{~b}$ \\
\hline E. A & $74,73 \mathrm{a}$ & $197,99 \mathrm{ab}$ & $652,37 \mathrm{a}$ & $1.139,02 \mathrm{a}$ \\
\hline CV $(\%)$ & 20,4 & 19,7 & 10,6 & 11,1 \\
\hline
\end{tabular}

$\mathbf{T}=$ Testemunha (sem adubação), A.Q = Adubação química, E.B = Esterco bovino, E.O = Esterco ovino, E.A = Esterco de aviário. Médias seguidas de mesma letra na coluna, não diferem entre si pelo teste de Tukey a $1 \%$ de probabilidade.

Para a matéria seca da parte aérea não ocorreram diferenças significativas aos 12 e 32 dias após a emergência (DAE) comportamento semelhante ao encontrado na matéria verde na parte aérea. Aos 22 dias destacaram a adubação química (A.Q) e esterco de aviário (E.A) diferindo dos demais tratamentos pelo teste Tukey $(\mathrm{P}<0,05)$ de probabilidade. (tabela 6). Aos 42 dias após a emergência (DAE) ocorreu diferença significativa pelo teste de Tukey a $(\mathrm{P}<0,05)$ destacando-se a adubação com cama de aviário que comportou de forma positiva com 215,66 g comparados com outros tratamentos.

O bom desempenho do tratamento (E.A) aos 42 DAE, tanto na matéria verde como na seca da parte aérea (tabela 5 e 6) pode está atribuído a sua eficiência em liberar os nutrientes ficando disponível para a planta suprindo a necessidades nutricionais do milho. Tal fenômeno promoveu a melhoria das suas condições físicas, químicas e biológicas e proporcionou melhor aproveitamento dos nutrientes originalmente presentes nele (MARCHESINI et al., 1988). 
Como também o teor $\mathrm{K}$ na cama de aviário bem superior as demais fontes orgânicas (esterco bovino e de ovino) (tabela 2). Segundo (FERNANDES., 2006) o K é elemento essencial para o crescimento, desenvolvimento e maturação dos grãos frutos dos vegetais. O mesmo autor relata que as necessidades de K para o ótimo crescimento das plantas situam-se na faixa de 20 - $50 \mathrm{~g} \mathrm{~kg}^{-1}$ da massa das partes vegetativas secas da planta. Sendo que teor de $\mathrm{K}\left(26,9 \mathrm{~g} \mathrm{~kg}^{-1}\right)$ encontrado na biomassa (E. A) ficou acima da faixa mínima, descrito na tabela 7 .

Tabela 6- Matéria seca da parte aérea em cada coleta para os diferentes tratamentos, na cultura do milho crioulo. IFPB, Sousa - PB, 2014.

\begin{tabular}{|c|c|c|c|c|}
\hline \multirow{3}{*}{ Tratamentos } & \multicolumn{4}{|c|}{ MATÉRIA SECA DA PARTE AÉREA (g/planta) } \\
\hline & \multicolumn{4}{|c|}{ Dias após emergência (DAE) } \\
\hline & 12 & 22 & 32 & 42 \\
\hline $\mathrm{T}$ & $7,86 \mathrm{a}$ & $18,91 \mathrm{~b}$ & $92,90 \mathrm{a}$ & $112,00 \mathrm{~b}$ \\
\hline A.Q & $4,71 \mathrm{a}$ & 27,97 a & $97,09 \mathrm{a}$ & $125,00 \mathrm{~b}$ \\
\hline E. B & $5,14 \mathrm{a}$ & $24,97 \mathrm{~b}$ & $85,06 \mathrm{a}$ & $124,33 \mathrm{~b}$ \\
\hline E. $\mathrm{O}$ & $6,68 \mathrm{a}$ & $17,22 \mathrm{~b}$ & $95,23 \mathrm{a}$ & $121,66 \mathrm{~b}$ \\
\hline E. A & $7,81 \mathrm{a}$ & $27,30 \mathrm{a}$ & $97,38 \mathrm{a}$ & $215,66 \mathrm{a}$ \\
\hline CV (\%) & 19,8 & 14,7 & 9,7 & 8,6 \\
\hline
\end{tabular}

$\mathbf{T}=$ Testemunha (sem adubação), A.Q = Adubação química, E.B = Esterco bovino, E.O = Esterco ovino, E.A = Esterco de aviário. Médias seguidas de mesma letra na coluna, não diferem entre si pelo teste de Tukey a $5 \%$ de probabilidade.

Os valores médios de nitrogênio encontrados na biomassa do milho, não apresentaram diferença aos 12, 22 e 32 (DAE), no entanto, foram superiores os tratamentos E.O, A.Q e E.B respectivamente, favoreceram maiores índices de absorção de nitrogênio pelo milho nos diferentes períodos de crescimento (Tabela 7). Nos 42 (DAE) os teores de nitrogênio apresentaram diferenças significativas, no qual as maiores absorção ocorreram com A.Q, E.B e E.A.

Tabela 7- Acumulo de nitrogênio na biomassa do milho crioulo após aplicação de fontes orgânicas e mineral. IFPB, Sousa $\mathrm{PB}, 2014$.

\begin{tabular}{|c|c|c|c|c|}
\hline \multirow{3}{*}{ Tratamentos } & \multicolumn{4}{|c|}{ N (g. kg $\left.{ }^{-1}\right)$} \\
\hline & \multicolumn{4}{|c|}{ Dias após emergência (DAE) } \\
\hline & 12 & 22 & 32 & 42 \\
\hline $\mathrm{T}$ & $31,85 \mathrm{a}$ & $22,80 \mathrm{a}$ & $22,34 \mathrm{a}$ & $15,37 \mathrm{c}$ \\
\hline A.Q & $33,41 \mathrm{a}$ & 36,46 a & $20,82 \mathrm{a}$ & $20,27 \mathrm{a}$ \\
\hline E. B & $33,74 \mathrm{a}$ & $31,79 \mathrm{a}$ & $22,52 \mathrm{a}$ & $19,12 \mathrm{ab}$ \\
\hline E. $\mathrm{O}$ & $34,82 \mathrm{a}$ & $31,68 \mathrm{a}$ & $20,36 \mathrm{a}$ & $17,42 \mathrm{bc}$ \\
\hline E. A & $30,86 \mathrm{a}$ & $30,04 \mathrm{a}$ & $21,19 \mathrm{a}$ & $19,07 \mathrm{ab}$ \\
\hline $\mathrm{CV}(\%)$ & 10,08 & 15,91 & 7,57 & 4,73 \\
\hline
\end{tabular}

T = Testemunha (sem adubação), A.Q = Adubação química, E.B = Esterco bovino, E.O = Esterco ovino, E.A = Esterco de aviário. Médias seguidas de mesma letra na coluna, não diferem entre si pelo teste de Tukey a $1 \%$ de probabilidade.

No geral, os maiores teores de nitrogênio absorvido pelas plantas de milho foram alcançados no período de 12 e 22 (DAE), provavelmente devido a adubação de fundação e de cobertura, que refletiram de forma positiva na disponibilidade de $\mathrm{N}$ refletindo numa maior absorção deste nutriente na fase inicial na planta do milho. Ficando ainda na faixa (27,5 a 32,5 $\mathrm{g} \mathrm{Kg}^{-1}$ ) considerável adequada para a cultura do milho (MALAVOLTA et. al., 1997).

Primo et. al. (2012) avaliando a contribuição da adubação orgânica da absorção de nutriente e produtividade de milho, verificou que os maiores teores de nitrogênio na biomassa foram alcançados no período de 30 dias, comportamento semelhante encontrado neste trabalho.

Os valores médios de fósforo encontrados na biomassa do milho não apresentaram diferenças significativas aos 12, $22 \mathrm{e}$ 42 (DAE). Aos 12 dias os maiores valores encontrados foram os dos tratamentos E. B e E.A, aos 22 dias os maiores resultados foram os tratamentos E.B e E.O. Aos 42 dias o maior resultado encontrado foi o tratamento E. B. (tabela 8). Aos 32 (DAE) houve diferença significativa entre os tratamentos testados, sendo que o E. B, e o E. O se destacaram superiores dos demais. De acordo com Bull (1993) para o P e o K, o pico de absorção ocorre entre 80 -
100 e 75 DAE, respectivamente. Isso Explica o baixo acúmulo de $\mathrm{P}$ na biomassa, pois as coletas do material foram realizadas somente até aos $42 \mathrm{DAE}$.

Percebe-se que o tratamento E. B favoreceu maiores índices de absorção de fósforo pelo milho nos diferentes períodos de crescimento. Sendo que o maior período de absorção foi aos $32 \operatorname{DAE}\left(2,98 \mathrm{~g} \mathrm{~kg}^{-1}\right)$, pois em todos os processos metabólicos que envolvem gastos de energia, desde a absorção de nutrientes até a formação dos diferentes órgãos, há participação direta ou indireta de P (CRUZ et al., 1996).

Com relação aos teores de $\mathrm{P}$, há, contudo, trabalhos que mostram a participação da matéria orgânica, reduzindo a adsorção de $\mathrm{P}$ em solos, por meio de ácidos orgânicos adsorvidos bloqueando sítios de adsorção e/ou solubilizando estes oxidróxidos e reduzindo suas superfícies de adsorção (Guppy et al., 2005), fato este que pode ser explicado pelo esterco constituir a principal fonte de nutrientes, principalmente $\mathrm{N}$ e $\mathrm{P}$ e de matéria orgânica, nas áreas de produção de culturas de subsistência, no agreste e no semiárido brasileiro, entretanto, quando aplicado combinado com adubos verdes como, por exemplo, a gliricídia, os resultados foram significativos (Menezes \& Salcedo, 2007; Marin et al., 2007). 
Percebe-se na tabela 9 que os maiores valores médios de absorção deste nutriente foi reduzida ao longo do período de potássio foram obtidos aos 12 DAE. A partir deste período a coleta.

Tabela 8- Acumulo de fósforo na biomassa do milho crioulo após aplicação de fontes orgânica e mineral. IFPB, Sousa - PB, 2014.

\begin{tabular}{|c|c|c|c|c|}
\hline \multirow{3}{*}{ Tratamentos } & \multicolumn{4}{|c|}{$P\left(g \mathrm{~kg}^{-1}\right)$} \\
\hline & \multicolumn{4}{|c|}{ Dias após emergência (DAE) } \\
\hline & 12 & 22 & 32 & 42 \\
\hline $\mathrm{T}$ & $1,94 \mathrm{a}$ & $2,11 \mathrm{a}$ & $1,69 \mathrm{~b}$ & $1,93 \mathrm{a}$ \\
\hline A.Q & $1,94 \mathrm{a}$ & $2,07 \mathrm{a}$ & $1,90 \mathrm{~b}$ & $1,88 \mathrm{a}$ \\
\hline E. B & $1,99 \mathrm{a}$ & $2,15 \mathrm{a}$ & $2,98 \mathrm{a}$ & $2,01 \mathrm{a}$ \\
\hline E. $\mathrm{O}$ & $1,80 \mathrm{a}$ & $2,16 \mathrm{a}$ & $2,93 \mathrm{a}$ & $1,87 \mathrm{a}$ \\
\hline E. A & $2,09 \mathrm{a}$ & $2,04 \mathrm{a}$ & $1,90 \mathrm{~b}$ & $1,89 \mathrm{a}$ \\
\hline CV (\%) & 9,7 & 7,0 & 10,1 & 5,6 \\
\hline
\end{tabular}

Tabela 9- Acumulo de potássio na biomassa do milho crioulo após aplicação de fontes orgânica e mineral. IFPB, Sousa - PB, 2014.

\begin{tabular}{ccccc}
\hline & \multicolumn{4}{c}{ K (g. $\mathbf{~ k g ~}^{\mathbf{- 1}}$ ) } \\
\cline { 2 - 5 } Tratamentos & 12 & 22 & Dias após emergência (DAE) & 42 \\
\hline T & $42,26 \mathrm{a}$ & $31,59 \mathrm{ab}$ & $19,56 \mathrm{~b}$ & $17,16 \mathrm{~b}$ \\
A.Q & $41,13 \mathrm{a}$ & $29,69 \mathrm{~b}$ & $27,46 \mathrm{a}$ & $22,59 \mathrm{a}$ \\
E. B & $39,59 \mathrm{a}$ & $40,62 \mathrm{a}$ & $24,09 \mathrm{ab}$ & $17,16 \mathrm{~b}$ \\
E. O & $43,49 \mathrm{a}$ & $39,99 \mathrm{a}$ & $24,29 \mathrm{ab}$ & $23,93 \mathrm{a}$ \\
E. A & $38,76 \mathrm{a}$ & $25,33 \mathrm{~b}$ & $19,36 \mathrm{~b}$ & $26,93 \mathrm{a}$ \\
\hline CV (\%) & 4,8 & 9,9 & 8,8 & 7,1
\end{tabular}

T = Testemunha (sem adubação), A.Q = Adubação química, E.B = Esterco bovino, E.O = Esterco ovino, E.A = Esterco de aviário. Médias seguidas de mesma letra na coluna, não diferem entre si pelo teste de Tukey a $1 \%$ de probabilidade.

Houve diferença significativa aos 22, 32 e 42 (DAE). Aos 22 dias o maior resultado encontrado foi referente ao tratamento E. B, seguido do E. O. Aos 32 dias a maior absorção ocorreu com o A.Q, seguido do E.B e E. O. Aos 42 dias o tratamento com C. A foi superior dos demais tratamentos.

Segundo Malavolta et. al. (1997) os teor dentro da faixa de 17 a $35 \mathrm{~g} \mathrm{gk}^{-1}$ são considerados adequado para a cultura do milho. Neste caso, os teores médios encontrados neste trabalho estão dentro desta faixa, isso implica que as diferentes fontes utilizadas contribuiu de forma positiva no desenvolvimento da cultura do milho crioulo.

Percebe-se que o maior acúmulo do potássio ocorreu dos 12 aos 22 DAE, Resultado semelhante foi encontrado por Borin et al (2010) e Primo et al. (2012) estudando absorção, acúmulo e exportação de macronutrientes no milho doce cultivado em condições de campo verificou que o potássio apresentou alta taxa de acúmulo nos primeiros 30 dias de desenvolvimento, com ritmo de absorção superior ao $\mathrm{N}$.

\section{CONCLUSÕES}

As fontes orgânicas são promissoras na substituição total á adubação química, com destaque para o esterco de aviário.

A extração de $\mathrm{N}$ pela planta seguiu a seguinte ordem: esterco ovino, adubação química, esterco bovino e adubação química, de acordo com as datas coletadas.

A extração de $\mathrm{P}$ pela planta seguiu a seguinte ordem: esterco aviário, esterco ovino, esterco bovino e esterco bovino, de acordo com as datas coletadas.
A extração de $\mathrm{K}$ pela planta seguiu a seguinte ordem: esterco ovino, esterco bovino, adubação química e esterco de aviário, de acordo com as datas coletadas.

\section{REFERÊNCIAS BIBLIOGRÁFICAS}

ANDRADE, A. G. DE; HAAG, H. P.; OLIVEIRA, G. D. DE e SARRUGE, J. R. Acumulação diferencial de nutrientes em cinco cultivares de milho (Zeamays). Crescimento. Anais da Escola Superior de Agricultura Luis de Queiroz, Piracicaba, v. 32, p. 115-149, 1975.

ANDRADE, J. A. C. \& FILHO, J. B. M. Quantitativevariation in the tropical maizepopulation, ESALQ-PB1. Scientia Agrícola, v.65, n.2, p.174-182, 2008.

BORIN, A. L. D. C.; LANA, R. M. Q.; PEREIRA, H. S.; Absorção, acúmulo e exportação de macronutrientes no milho doce cultivado em condições de campo. Revista Ciência Agrotécnica., Lavras, v. 34, Edição Especial, p. 1591-1597, 2010

BULL, L. T. Nutrição mineral do milho. In: BULL, L. T.; CANTARELLA, H. (Ed.) Cultura do milho: fatores que afetam a produtividade. Piracicaba: POTAFOS, 1993. p. 63-145. 
CALDARELLI, C. E; BACCHI, M. R. P. Fatores de influência no preço do milho no Brasil. Nova econ. $v$. 22 n.1 Belo Horizonte Jan./Apr. 2012. Disponível em: http://dx.doi.org/10.1590/S0103-63512012000100005. Acesso em: 20 de Agosto 2013.

COMISSÃO ESTADUAL DE FERTILIDADE DO SOLO, Recomendação de adubação para o Estado de Pernambuco, $2^{\mathrm{a}}$ aproximação, Pernambuco, 2008.

CRUZ, J.C.; MONTEIRO, J.A.; SANTANA, D.P.; GARCIA, J.C.; BAHIA, F.G.F.T.C.; SANS, L.M.A.; PEREIRA FILHO, I.A. Recomendações técnicas para o cultivo do milho. 2.ed. Brasília: Embrapa-SPI, 1996. 204p.

CRUZ, J. C. KONZEN, E. A. PEREIRA FILHO, I. A. F. MARRIEL, I. E. CRUZ, I. DUARTE, J. DE. O. OLIVEIRA, M. F. ALVARENGA, R. C. Produção de milho orgânico na agricultura familiar. Circular Tecnico 81. Embrapa Sete Lagoas MG. 2006. Disponível em: http://www.diadecampo.com.brCirc_81.pdf. Acesso em: 02 de nov 2013.

DUARTE, J. de O. Introdução e importância econômica do milho. In: CRUZ, J. C.; VERSIANI,R. P.; FERREIRA, M. T. R. (Ed.). Sistema de produção - Milho. Embrapa Milho e Sorgo, 2002.

DAGA, J.; RICHART, A.; NOZAKI, M. H.; ZANETTI, T. A.; ZANETTI, R. D. Desempenho do milho em função da adubação química e orgânica. Synergismus scyentifica UTFPR, Pato Branco, 04(1) . 2009.

EMBRAPA. Centro Nacional de Pesquisa de Solos. Sistema Brasileiro de Classificação de Solos. 2. ed. Brasília: EMBRAPA, 2006. 306 p.

GUARESCHI, R. F., SILVA, A.; SILVA JUNIOR, H.R. da; PERIN, A., GAZOLLA, P. R. Adubação orgânica na produção de biomassa de milho em Latossolo de cerrado. Global Scienceand Technology, Rio Verde, v. 06, n. 02, p.66 - 73, mai/ago. 2013.

GUPPY, C.N.; MENZIES, N.W.; WOOD, P.W.; BLAMEY, F.P.C. Competitive sorption reactions between phosphorus and organic matter in soil: a review. Australian Journal of Soil Science, v.43, n.2, p.189-202, 2005.

MALAVOLTA, E.; VITTI, G.C.; DE OLIVEIRA, S.A. Avaliação do estado nutricional das plantas: Princípios e aplicações. Piracicaba: POTAFOS, 1989. 201 p.

MALAVOLTA, E.; GOMES, F. P.; ALCARDE, J. C. Adubos e Adubações. São Paulo: Nobel, 2002. p. 29-110.

MALAVOLTA, E.; VITTI, G. C.; OLIVEIRA, S. A. Avaliação do estado nutricional das plantas: princípios e aplicações. 2. ed. Piracicaba, Associação Brasileira para a pesquisa da Potassa e do Fosfato - POTAFOS, Piracicaba, 1997, 319p.
MARCHESINI, A.; ALLIEVI, L.; COMOTTI, E.; FERRARI, A. Long-term effects of quality compost treatment on soil. Plant and Soil, v.106, p.253-261, 1988.

MARIN, A.M.P.; MENEZES, R.S.C; SALCEDO, I.H. Produtividade de milho solteiro ou em aléias de gliricídia adubadas com duas fontes orgânicas. Pesquisa Agropecuária Brasileira, v.42, n.5, p.669-677, 2007.

MELGAR, A. J.; TORRES DUGGAN, M. Manejo de la Fertización em Maiz. Proyecto Fertilizar EEA INTA Pergamino, Argentina. 2004.

MENEGUETTI, G.A.; GIRARDI, J.L.; REGINATTO, J.C. Milho crioulo: tecnologia viável e sustentável. Agroecologia e desenvolvimento rural sustentável. Porto Alegre, v.3, n.1, 2002.

MENEZES, R.S.C; SALCEDO, I.H. Mineralização de N após incorporação de adubos orgânicos em um Neossolo Regolítico cultivado com milho. Revista Brasileira de Engenharia Agrícola e Ambiental, v.11, n.4, p.361-367, 2007.

PEREIRA JUNIOR, E. B.; HAFLE, O. M.; OLIVEIRA, F, T. de.; OLIVEIRA, F. H. T. de.; GOMES, E. M. Produção e qualidade de milho-verde com diferentes fontes e doses de adubos orgânicos. Revista Verde de agroecologia e desenvolvimento sustentável (Mossoró - RN), v. 7, n. 2, p 277-282, abr-jun, 2012 .

PIRES, J.F.; JUNQUEIRA, A.M.R. Impacto da adubação orgânica na produtividade e qualidade das hortaliças. Horticultura Brasileira, Brasília, v. 19, n. 2, p. 195, 2001.

PORTO, A. P. F. Cultivares de milho submetido a diferentes espaçamentos e manejos de capinas no planalto da conquista - BA. Dissertação. Vitória da conquista BA. 2010. Disponível em: http://www.uesb.br/mestradoagronomia/banco-dedissertacoes/2010/ana-paula-ferreira-porto.pdf.

PRIMO, D. C.; MENEZES, R. S. C.; SILVA, T. O. DA.; GARRIDO, M. S.; CABRAL, P. K. T. Contribuição da adubação orgânica na absorção de nutrientes e na produtividade de milho no semiárido paraibano. Rev. Bras. Ciênc. Agrár. Recife, v.7, n.1, p.81-88, 2012.

SILVA, R. G.; GALVÃO, J. C. C.; MIRANDA, G. V.; SILVA, D. G.; ARNHOLD, E.;produtividade de milho em diferentes sistemas produtivos. Revista Verde (Mossoró RN Brasil) v.2, n.2, p. 136-141 Julho/Dezembro de 2007. Disponível em: http://revista.gvaa.com.br

SILVA, F. DE A. S.; AZEVEDO, C. A. V. DE. Versão do programa computacional Assistat para o sistema operacional Windows. Revista Brasileira de Produtos Agroindustriais, Campina Grande, v.4, n.1, p71-78, 2002. 
SOUZA, J. L. de. Agricultura Orgânica - tecnologias para a produção de alimentos saudáveis. v.1, EMCAPA, Domingos Martins - ES, 179p., 1998.

SOUZA, J. L. de. Agricultura orgânica: tecnologias para a produção de alimentos saudáveis. Espírito Santo: ENCAPA, 1998. 176 p.

STIPP, S. R.; YAMADA, T. Nutrição e adubação do milho. Informações Agronômicas, Piracicaba, v. 44, p. 3-6, dez. 1988.
TAIZ, L.; ZEIGER, E. Fisiologia Vegetal. 3 ed. Porto Alegre. 2004.

TEDESCO, M. J.; GIANELLO, C.; BISSANI, C. A.; HOHNEN, H.; VOLKWEISS, S. J.; Análise de solo, plantas e outros materiais. Departamento de solos Faculdade de Agronomia Universidade Federal do Rio Grande do Sul, Porto Alegre, 1995.

VON PINHO, R. G.; BORGES, I. D.; PEREIRA, J. L. A. R.; REIS, M. C. Marcha de absorção de macronutrientes e acúmulo de matéria seca em milho. Revista Brasileira de Milho e Sorgo, v.8, n.2, p. 157-173, 2009. 